\title{
Bogency and Goodacies: On Argument Quality in Virtue Argumentation Theory
}

\author{
Fabio Paglieri
}

Goal-Oriented Agents Lab (GOAL)

Istituto di Scienze e Tecnologie della Cognizione (ISTC)

Consiglio Nazionale delle Ricerche (CNR)

Via S. Martino della Battaglia 44

00185 Roma

Italy

fabio.paglieri@istc.cnr.it

\begin{abstract}
Virtue argumentation theory (VAT) has been charged of being incomplete, given its alleged inability to account for argument cogency in virtue-theoretical terms. Instead of defending VAT against that challenge, I suggest it is misplaced, since it is based on a premise VAT does not endorse, and raises an issue that most versions of VAT need not consider problematic. This in turn allows distinguishing several varieties of VAT, and clarifying what really matters for them.
\end{abstract}

Résumé: On a reproché à la théorie des vertus argumentatives (TVA) d'être incomplète, car elle ne pourrait rendre compte du bien-fondé d'un argument à l'aide de ses propres ressources. Au lieu de défendre la TVA face à cette accusation, nous allons plutôt suggérer qu'une telle accusation est une méprise, car elle repose sur une prémisse que n'endosse pas la TVA et qu'elle soulève une question qui n'est pas problématique pour la plupart des versions de la TVA. Cela nous amènera à distinguer plusieurs variantes de la TVA et à clarifier ce qui est central chez ells.

Keywords: argument quality, cogency, conflicting virtues, relevance theory virtue argumentation theory.

\section{Introduction}

Virtue argumentation theory (henceforth, VAT) is a relatively new contender in the arena of argumentation theories - a martial metaphor that some virtue theorists may not be ready to endorse without reservation, by the way (see, e.g., Cohen, 1995). To the best of my knowledge, the name was coined by Andrew Aberdein as late as in 2007, in a paper where he outed Daniel Cohen as a sort of closeted virtue argumentation theorist, quoting persuasive textual evidence from Cohen's previous work $(2004,2005)$. However, Aberdein $(2007,2010 a)$ has made also abundantly clear that VAT is but the latest offspring of an 
illustrious scholarly tradition, to wit, virtue theory in general, dating back to ancient philosophy, and most notably to Aristotle's ethical writings. As it is well-known, that particular approach has been gaining a lot of momentum in recent years, in the context of virtue ethics (Foot, 1978; MacIntyre, 1981; Hursthouse, 1999) and positive psychology (Seligman \& Csikszentmihalyi, 2000), as well as in the area of virtue epistemology (Sosa, 1991; Zagzebski, 1996), which shares many topics of concern with argumentation theories. So it should not come as a surprise to see that VAT is currently prospering: for instance, "Virtues of Argumentation" was the topic of the latest international conference of the Ontario Society for the Study of Argument (Windsor, 22-25 May 2013), with Daniel Cohen featuring as one of the keynote speakers; nor is the relevance of VAT confined to argumentation theories, given that a non-specialistic philosophy journal such as Topoi is currently preparing a special issue on "Virtues and Arguments," guest edited by Andrew Aberdein and Daniel Cohen.

In spite of all these indications of success, the surest sign of the growing importance of VAT is the fact that it also attracted a fair share of criticism and doubt. Some of these were relatively mild, and would be better understood as constructive efforts to improve on this recent approach: so, for instance, Heather Battaly (2010) has argued that the frequent efforts at distinguishing fallacious and non-fallacious ad hominem arguments (e.g., Walton, 1998; Tindale, 2007; Woods, 2007) should be framed in the context of virtue epistemology. If Battaly is right, then also several scholars who do not currently regard themselves as virtue theorists ought to take argumentative virtues into greater consideration. Other critical commentaries, however, have been less kindly disposed towards VAT: this is the case with a recent article by Tracy Bowell and Justine Kingsbury (2013), in which VAT was charged with an inability to offer an alternative account of what a good argument is, and in particular of validity. That concern was later answered by Aberdein (2014), and the present paper also intends to address the same problem, although from a very different angle. In fact, in what follows I will engage in a modest effort at metaargumentative reconstruction (in the sense of metaargumentation detailed in Finocchiaro, 2013), to make the following points:

- the key problem with Bowell and Kingsbury's criticism is that it aims at the wrong polemical target;

(C) Fabio Paglieri. Informal Logic, Vol. 35, No. 1 (2015), pp. 65-87. 
- in contrast, taking that criticism as central and thus responding to it in detail, as Aberdein did, has the undesirable consequence of further derailing the discussion on VAT towards issues that are tangential to its aims and unlikely to be particularly productive;

- since there are more pressing theoretical concerns with VAT, priority should be given to those matters, by both proponents and critics of VAT;

- ironically, the whole debate analysed here exemplifies one of those key concerns, to wit, how to establish the virtuous path when multiple argumentative virtues conflict with each other.

While my analysis is intended to defuse Bowell and Kingsbury's criticism against VAT, it does not end up making their observations useless. On the contrary, along the way I will show that their contribution works well as a litmus test: how one reacts to their argument reveals the kind of virtue theorist that person is prepared to be.

\section{A case against VAT — and why it doesn't matter}

Bowell and Kingsbury set out to prove that "virtue argumentation theory does not offer a plausible alternative to a more standard agent-neutral account of good argument" (2013, p. 23). In order to make that point, they employ an argument (denoted as BK from now on) that can be reconstructed as follows:

1. They define a good argument in terms of justification, as "an argument that provides, via its premises, sufficient justification for believing its conclusion to be true or highly probable, or for accepting that the course of action it advises is one that certainly or highly probably should be taken" (p. 23). ${ }^{1}$

\footnotetext{
${ }^{1}$ While Bowell and Kingsbury never mention the notion of cogency in their article, their definition of argument quality resonates with the so-called RSA criteria for argument cogency: relevance, sufficiency, and acceptability (Johnson \& Blair, 1977; Johnson, 2000).

${ }^{2}$ This should not be necessarily construed as an oversight on their part: the debate on VAT has developed substantially over the years, so the aims and scope of that theory are arguably clearer now than they were at the time when
}

(C) Fabio Paglieri. Informal Logic, Vol. 35, No. 1 (2015), pp. 65-87. 
2. They emphasize two main factors for argument evaluation: the truth of the premises, and the structural link between premises and conclusions.

3. They argue that considerations on the arguer's character can be pertinent to establish the truth of her claims, including the premises of her arguments (e.g., in legitimate ad hominem), but are never relevant to evaluate the structure of the argument-which is what matters for validity.

4. They consider and reject two apparent counterexamples to 3: inductive arguments whose evaluation may be affected by unstated facts, and arguments based on reasoning too complicated for the untrained to follow (such as the Monty Hall puzzle).

5. They conclude that argument assessment cannot be reduced to considerations on the arguer's character: "virtue argumentation theory cannot be the whole story when it comes to argument evaluation" (p. 31, my emphasis).

In his response to BK, Aberdein (2014) mostly focused on points 3 and 4 above: that is, he tried to show how the arguer's character can provide insight on the structure of the argument and its validity (contra 3), and how this happens also in those counterexamples that Bowell and Kingsbury thought to have rejected (contra 4). I will not discuss here whether Aberdein is successful in his efforts, because I want instead to put pressure on steps 1 and 2 of BK, as well as inviting further reflection on 5.

The starting point of BK is in how argument quality is defined: this is a truly pivotal move, because the criticism is aimed at argument evaluation, but it hinges on alleged limits of VAT in dealing with the structure of arguments, and thus primarily with their validity, or lack thereof. So, unless validity (or its broad-minded cousin, cogency) plays a key role in argument assessment, there is no reason for concern. Bowell and Kingsbury are of course aware that VAT is unlikely to endorse a definition of argument quality that reduces it to cogency, and this is how they frame the issue: "This [i.e., their own definition of argument quality] is not an account of good argument that a virtue argumentation theorist would accept. The virtue theorist thinks that what makes an argument good is that the person presenting it has argued well, whereas we think that what makes it the case that an arguer has argued well is that they have presented an argument that is good in the sense described in the previous paragraph" (2013, p. 23). Unfortunately, this strikes me as a particularly unhelpful way of describing the situation, akin

(C) Fabio Paglieri. Informal Logic, Vol. 35, No. 1 (2015), pp. 65-87. 
to the proverbial dilemma "which came first, the chicken or the egg?"- we all know how that sort of discussion leads nowhere. In particular, here Bowell and Kingsbury do not mention the substantive reasons that prompted VAT to focus on the arguer's character in the first place. ${ }^{2}$

Looking at the literature, it is absolutely clear that VAT was borne out of a deep-seated suspicion towards a definition of good argument too much focused on structural features, given the latter inability to justify people's intuitions on argument quality. Consider for instance the following (real) textbook example of an allegedly good argument: "Both Pierre and Marie Curie were physicists. Therefore, Marie Curie was a physicist" (quoted in Cohen, 2013, p. 479). If we look at this piece of text with a rich notion of "quality" in mind, we find it hard to hold it in high esteem, since it does not seem very "good" in any meaningful sense. On the contrary, it is manifestly bad in a variety of respects: uninformative, trivial, pedantic - you name it. That is why some people may even have what I like to call "a Cohen's reaction" to it-something like "Really? That's your example of a good argument?!" (again, Cohen, 2013, p. 479, emphasis in the original).

Let us name this the problem of balidity: it hinges on the fact that some inferential structures, in spite of their unquestioned validity, are still terminally bad qua arguments. Nor is balidity a rare affliction: as a case in point, consider themother-of-all-enthymemes (assuming enthymeme to be a female gendered noun, which is something I was unable to establish): "Socrates is a man, therefore Socrates is mortal". If reconstructed as a truncated syllogism with the implicit premise "All men are mortal", it is perfectly valid-yet it is still not a good argument, other than for the purpose of illustration (which is, not surprisingly, the only use it ever had). Could anyone seriously picture Aristotle, or anyone else, using this line as a piece of real-life arguing, e.g., to persuade an interlocutor of the mortality of Socrates? Certainly not: it is only meant, and always was, as an example, not an argument.

A tempting way out of the problem of balidity is to insist that balid arguments, as disappointing as they may be in certain respects, still retain some measurable value. For instance, even the standard exemplars of syllogism are informative in some

\footnotetext{
${ }^{2}$ This should not be necessarily construed as an oversight on their part: the debate on VAT has developed substantially over the years, so the aims and scope of that theory are arguably clearer now than they were at the time when Bowell and Kingsbury wrote their article. In fact, I believe their paper contributed (and may still contribute) to engender further theoretical development and clarification of VAT.
}

(C) Fabio Paglieri. Informal Logic, Vol. 35, No. 1 (2015), pp. 65-87. 
respects, e.g., by making manifest what it is possible to know $a$ priori on the basis of their premises: if we know that Socrates is a man, and that all men are mortal, then we can legitimately claim to know that Socrates is mortal. ${ }^{3}$ This is absolutely correct, but also entirely beside the point: nobody wants to claim that validity is a useless notion-indeed, that would make it hard to explain why philosophers have obsessed over it for millennia. The point that balid arguments make is simply that validity is no guarantee for argumentative value. Granted, balid arguments can be wonderful examples and powerful tools for the purpose of philosophical analysis. What they are not is good arguments; and this claim is based on an appeal to intuition, not on some stipulation of what constitutes a good argument.

It is also worth noticing that balidity is just a narrower manifestation of a bigger issue, that I shall call the problem of bogency: the examples discussed above are not only valid, but also cogent - at least on some interpretation of the notion of cogency. Take the well-known and widely accepted RSA criteria for argument cogency: the premises are to be relevant, sufficient, and acceptable (Johnson \& Blair, 1977; Johnson, 2000). Now look again at the Curie and Socrates examples: they satisfy these criteria (even if you add truth to the mix, as some have suggested we ought to; see Johnson, 1990; Allen, 1998), so they count as cogent arguments on the RSA definition. ${ }^{4}$ Yet they remain bad arguments, in spite of their cogency.

At this point, someone might object to the whole idea of bogency, on the ground that instances like those mentioned above are best understood as not argumentative at all. Simply put, the idea would be to claim that a certain linguistic expression, even though it conveys a clear (and, in this case, valid) inference pattern, may serve a function that has nothing to do with arguing-e.g., exemplifying what an argument is. However, this view has two main flaws: first, it is inconsistent with presenting similar sentences as tokens of the type "argument", and it fails to explain how they could exemplify what is supposed to be "good" in an argument (by comparison, consider an example of a delicious apple, which is typically an apple with the appropriate qualities, not something else entirely); second, scholars have been treating similar cases as

\footnotetext{
${ }^{3}$ I am grateful to an anonymous reviewer for drawing my attention to this potential objection to balidity.

${ }_{4}^{4}$ More precisely, those arguments count as cogent if one endorses a definition of premissary relevance (Blair, 1992) as reducible to the intuitive notion of having a bearing on the conclusion, as it is standardly done in argumentation theory with respect to cogency (Govier, 1985; Johnson, 2000; Vorobej, 2006). More on this later on.
}

(C) Fabio Paglieri. Informal Logic, Vol. 35, No. 1 (2015), pp. 65-87. 
arguments (in fact, prototypical ones) for several centuries, so a very convincing error theory would be required to explain how we were all so deeply mistaken. Absent such a theory, it is much more parsimonious to treat these cases as arguments that are cogent and yet bad (bogent, for short), and therefore try to provide an account of argument quality that does not reduce it to cogency.

In this perspective, which is the one endorsed by VAT, bogent arguments are instances in which cogency does not rescue the argument from its badness. As Cohen quipped, only someone with logical blinders on $(2013$, p. 479) could fail to see their spectacular lack of value, in spite of their cogency. What Bowell and Kingsbury omit to notice is that bogent arguments are also the main motivation for VAT. So, a better reconstruction of the VAT standpoint on argument quality would be the following: the virtue theorist thinks that what makes an argument good cannot just be cogency (given the existence of bogent arguments), and thus conceives argument quality as depending on the act of arguing well. This is not just a matter of perspective, but rather a substantial disagreement on what counts as good argument, based on a verifiable appeal to people's intuitions.

The upshot is that Bowell and Kingsbury give us a definition in which cogency is necessary and sufficient for quality, whereas virtue theorists reject sufficiency, and may also reject necessity, depending on how radical they are (more on this later on). So BK argues against VAT from a premise that VAT explicitly rejects: it is not hard to see that this is unlikely to produce much progress. Of course, Bowell and Kingsbury (or any other critic of VAT, for that matter) could still argue that VAT is wrong in rejecting a cogency-based definition of argument quality: doing so would require explaining why bogency is not really a problem for argument assessment. This may indeed be a worthy endeavour, albeit personally I consider it unlikely to succeed. However, it does not seem to be part of what Bowell and Kingsbury set out to do in their paper, where they were rather just stipulating a definition of argument quality, one that VAT does not endorse, and then use it to criticize VAT, without explaining why VAT ought to endorse that definition in the first place.

\section{Argument quality and argumentative luck}

There is at least another reason why virtue theorists do not endorse step 1 of BK, and are right not to. Accepting a cogency-

(C) Fabio Paglieri. Informal Logic, Vol. 35, No. 1 (2015), pp. 65-87. 
based definition of argument quality would make VAT unduly vulnerable to a standard objection raised against virtue theoretical approaches, namely, the luck objection (Pritchard, 2003, 2008, 2012). Simply put, it goes as follows: if the required feat, e.g., producing an argument of high quality, that VAT would ascribe to particular virtues of the arguer can often and easily be achieved by mere happenstance, then the link between virtuous dispositions and virtuous behaviour becomes too tenuous for the former to explain the latter. The matter has been often discussed in the context of epistemology, where it is known as the problem of epistemic luck (how luck affects the acquisition of knowledge, and how this impacts on epistemology): let us focus instead on argumentative luck, i.e., how luck affects the elaboration of good arguments, and how this impacts on argument theory. In fact, whenever VAT tries to present certain virtues as necessary for argument quality, a single case of argumentative good luck (i.e., a good argument being produced by chance, in spite of substantial deficits in the arguer's relevant dispositions) provides a counterexample to the theory; conversely, if VAT wants to show that a set of virtues is jointly sufficient for argument quality, then it must be ready to defuse any apparent instance of argumentative bad luck (i.e., a bad argument being produced by factors outside of the arguer's control, in spite of her deployment of all the relevant virtues).

Argumentative luck has received very little attention in argumentation theory, even in the context of $\mathrm{VAT}^{5}$-although some proponents of VAT have discussed epistemic luck in other contexts, e.g., the philosophy of mathematics (Aberdein, 2010b). I think this is a pity, because the issue has much to offer, and not only to the debate on VAT. For instance, while

\footnotetext{
5 A notable exception is the following passage by Cohen: "Isn't an accidentally produced good argument just as good as a virtuously produced one? Even if we ignore the equivocation on both 'good' and 'argument' in this question, the answer is still ' $\mathrm{No}$ ' and for the same reasons that accidentally true beliefs do not count as knowledge. Otherwise, arguers would not have the requisite 'ownership' of their arguments, a relation that grounds responsibility and the assignment of blame and credit" (2013, pp. 482-483). While this is a respectable position to maintain, it requires further elaboration: in the context of epistemology, Pritchard (e.g., 2012) has convincingly argued that discussion of epistemic luck would be much improved by careful scrutiny of what such luck exactly is and entails: mutatis mutandis, the same is true for discussions of argumentative luck. Moreover, Cohen owes us some clarification on what the required ownership precisely is (and are those scare quotes? If so, why?), why ownership should be required for arguments (do we own our arguments in the same sense in which we own our mental attitudes, such as beliefs and goals?), and what is the relationship between that ownership and argumentative virtues (do the latter determines the former? If so, how?).
}

(C) Fabio Paglieri. Informal Logic, Vol. 35, No. 1 (2015), pp. 65-87. 
relatively simple solutions are available for VAT to the problem of argumentative good luck (e.g., by making certain virtues typically conducive of good argumentation, rather than either necessary or sufficient), argumentative bad luck highlights the fact that no single individual is fully in control of any argument of minimal complexity, and thus VAT should look not only at the virtues of arguers, but also at those of all the other players involved-e.g., intended audience, occasional bystanders, interested third parties that are being discussed, various types of supporting agents, external arbiters of the debate, and many more. Another way of putting the point is to note, as Cohen did, that "we need to expand the category of 'arguer' to include everyone who is relevant for the judgment that an argument is, or is not, fully satisfying" (2013, p. 480).

Be that as it may, my present purpose is not to assess how VAT fares against the problem of argumentative luck, but rather to note that accepting step 1 of BK would make that problem utterly intractable. It is easy to see why: on a cogency-based definition of argument quality, of the type proposed by Bowell and Kingsbury, the Curie argument mentioned above is a perfectly fine piece of arguing; however, it certainly does not take a genius to utter it, so it is perfectly possible to imagine a person that, albeit lacking any significant argumentative virtue, still managed to produce such a pearl of wisdom. That, according to step 1 of BK, would count as a "luck counterexample" to VAT. Similar counterexamples would be easy to multiply, and VAT would soon find itself surrounded by hordes of lucky argumentative dimwits, all clamouring for their arguments to be accepted as good and the walls of virtues to be torn down.

Which is all the more reason not to accept a cogencybased definition of argument quality, if you are in the business of doing VAT. The whole idea does not make much sense, on the face of it: why should anyone want to belabour on a fairly rich and complex theory of virtues, and then tie that theory to a definition of quality which is extremely narrow and pays only minimal attention to extra-textual features? On the contrary, a rich definition of argument quality, of the kind that virtue theorists have tried to flesh out in their writings (e.g., Cohen, 2004, 2005, 2009, 2013; Aberdein, 2007, 2010a, 2014), is much less vulnerable to the luck objection-not because it is immune to it (it is not), but because relevant counterexamples are definitely harder to find. If arguing well is a property of prolonged debates involving multiple stakeholders with complex agendas, and defining their quality requires balancing a variety of considerations pertaining to all the interested parties along

(C) Fabio Paglieri. Informal Logic, Vol. 35, No. 1 (2015), pp. 65-87. 
various dimensions, then the likelihood of arguments that are either good or bad by sheer luck may be almost negligible. Argumentative luck would still be a problem in principle, and a useful incitement to further develop VAT, but its practical significance would be abysmal.

\section{Varieties of VAT}

If we now turn to step 5 of $\mathrm{BK}$, it is worth noting that Bowell and Kingsbury (2013) tend to shift aim across their paper, or at least to leave open multiple interpretations of what exactly that aim is. Sometimes their critique of VAT is framed in terms of failure (e.g., "VAT does not offer a plausible alternative to a more standard agent-neutral account of good argument," p. 23), but more often they spell it out as a charge of incompleteness: e.g., "any agent-centered account that cannot accommodate [a cogency-based characterization of argument quality] will be unable to offer a complete account of good argument" (p. 24). Bowell and Kingsbury might not even consider these two positions as truly distinct, since in their view cogency is the crux of argument quality, therefore if VAT cannot give us cogency, then it is by and large a failure at evaluating arguments, period. However, for virtue theorists, who do not consider cogency as the crux of argument quality, the two charges are clearly different. In what follows I will stick to the more modest reading of Bowell and Kingsbury's thesis, as it is spelled out in point 5 of BK (taken from their own conclusions): "virtue argumentation theory cannot be the whole story when it comes to argument evaluation" (p. 31).

The question I want to pose is the following: Should virtue theorists be worried by this charge of incompleteness? The answer depends on what kind of virtue theorist one is prepared to be. To simplify, let us distinguish between:

- Moderate VAT: cogency is necessary but insufficient for argument quality; hence it is perfectly possible for an argument to be bogent, whereas all good arguments are also cogent.

- Radical VAT: cogency is neither sufficient nor necessary for argument quality-hence looking at cogency is a nonstarter to assess argument quality.

In a moment I will turn to the empirical question of what kind of virtue theorists are to be found "in the wild," taking as prime 
examples the leading proponents of VAT, Daniel Cohen and Andrew Aberdein. But first let us note that radical virtue theorists are by definition immunized against BK: if cogency is neither sufficient nor necessary for argument quality, who cares whether or not it depends on the arguer's character?

In looking at textual evidence, it would seem that Daniel Cohen takes a radical stance, at least on validity: "Valid reasoning is apparently neither necessary nor sufficient for an acceptable argument" (2013, p. 479). Although Cohen is quick to add that "acceptable" is not synonymous with "fully satisfying," this certainly sounds like an endorsement of radical VAT, as far as validity is concerned. Now, denying the sufficiency of validity for argument quality is not especially hard, since balid arguments make a pretty strong case in that direction, as discussed; ditto for bogency. But to reject necessity too, one must produce at least one instance (and possibly several) of an argument which is indisputably good, and yet not cogent, either because it is invalid, or because it lacks in one of the RSA criteria. In short, what radical virtue theorists have to give us is a goodacy, i.e., a good fallacy. This strikes me as something much harder to do. Yet Cohen thinks he can deliver on this, so let us turn again to his work for elucidation.

Unfortunately, I do not think his treatment of this particular point can really win the day for radical VAT. This is how Cohen argues against the necessity of cogency for argument quality:

Under certain circumstances, it is not necessarily unreasonable to overlook an argument's flaws. One might, for example, resort to a meta-argument like this: 'I can see that the argument doesn't work as it stands, but the conclusion is so attractive that I'm sure someone will be able to fix it. I'll accept this flawed one for now.' The French mathematician and physicist Henri Poincaré suggested that he sometimes operated this way: accepting a formula as a provisional lemma in proving theorems before he had any proof for that lemma. (2013, p. 479)

If we look at this as an example of a goodacy, I believe we are bound to be disappointed. After all, what is being accepted as good here is the conclusion, not the argument for it: while this is indeed a fairly common instance (we often have clear intuitions on certain matters, even when we lack the means to prove them to our satisfaction), this has little to do with the quality of the argument. In fact, by provisionally accepting something as a lemma, Poincaré was certainly not suggesting that he had a good proof for it—and indeed, the whole point of

(C) Fabio Paglieri. Informal Logic, Vol. 35, No. 1 (2015), pp. 65-87. 
provisionality is because you can get away with it for the time being in light of practical considerations, but sooner or later you will have to deliver "the whole thing." So I do not see metaarguments of the kind suggested by Cohen as convincing cases of goodacies.

In my view, if one really wants to be radical on VAT, then the most promising direction to take is looking at cases where cogency does not matter for the interested parties, rather than being objectively absent. Goodacies may or may not be the unicorns of argumentation, but there is no lack of instances in which people (i) experience an argumentative exchange as being fully satisfying, while (ii) bypassing careful consideration of cogency, or even (iii) regarding such considerations as a threat to the optimal flow of arguing they are currently experiencing. When you are having the time of your life animatedly discussing with your friends, scrutinizing the cogency of each other's arguments may very well be considered a fatal faux pas. Granted, presenting similar instances as evidence against the idea that cogency is necessary for argument quality is not without problem: a predictable, but far from trivial objection would be to note that, as long as mutual rational questioning of each other's arguments is out, then it is hard to see why we should insist in calling that particular activity "argumentation" at all. Still, it seems to me that similar cases are more promising for radical VAT than instances where lack of cogency is fully acknowledged, like the one discussed by Cohen, because in the latter situation the notion of "quality" does not truly apply to the argument, but rather to its conclusion.

However, my purpose here is not to defend a radical version of VAT, but rather to note that (i) it is not easy to be a radical virtue theorist, yet (ii) if you manage to hold to that particular position, then you do not need to worry at all about $\mathrm{BK}$. This, in turn, provides us with the intellectual resources to offer a streamlined, and possibly more informative reconstruction of BK. As far as I can see, Bowell and Kingsbury's line of argument can be summarized as follows:

$B K$, compact version: Unless radical VAT can be supported, either cogency can be determined by the arguer's character, or VAT does not provide a complete theory of argument evaluation.

Radical virtue theorists deny the premise (they are ready to argue for radical VAT), so they can ignore the disjunctive conclusion. Moderate virtue theorists, in contrast, have to decide whether they want to take the first or the second horn of it.

(C) Fabio Paglieri. Informal Logic, Vol. 35, No. 1 (2015), pp. 65-87. 
Again, their choice in that respect will tell us something on the kind of virtue theorist they intend to be, differentiating two subtypes of moderate VAT:

- Modest moderate VAT: cogency is necessary, albeit not sufficient, for argument quality, and moreover it is an aspect of quality that does not require considerations of character to be established.

- Ambitious moderate VAT: cogency is also considered necessary and non-sufficient for argument quality, but it is conceived as determined by virtue theoretical considerations, like any other facet of quality.

Aberdein, in his reply to BK (2014), seems to endorse the latter position: so here I am taking the liberty of outing him as an ambitious virtue theorist, in spite of his moderation. It is also worth noting that virtue theorists of Aberdein's persuasion, i.e., ambitious moderates, are the only ones that need take issue with BK. For the radicals, the challenge it poses is non-existent; for the modest moderates, accepting the charge of incompleteness is not a problem to start with, since they agree that argument evaluation, while requiring an appeal to the arguers' virtues to establish quality in general, does not need to make use of similar means in dealing with the specific problem of cogency. But, to paraphrase Bowell and Kingsbury, since cogency cannot be the whole story when it comes to argument evaluation, then leaving cogency outside of the scope of virtues does not make VAT any less necessary to understand argument quality. That is what makes modest moderates immune to BK.

But is modest moderate VAT a genuinely interesting theoretical option? I believe it is - or, at least, I argue that, prima facie, there is nothing wrong in being modestly moderate, when it comes to VAT. Two main reasons stand out for that claim: first, modest moderation is a very natural theoretical stance to have, with respect to VAT; second, one can be moderate in a very ambitious sense, that is, without making virtues any less crucial to argument evaluation. The first point I take to be rather self-evident. As discussed, from day one VAT presented itself as an attempt to move beyond cogency in assessing argument quality: as such, it was never necessarily committed to providing a complete theory of argument evaluation, especially in terms of cogency, because that is precisely what VAT is not interested in - at least not primarily. This brings us to the second point: VAT may be "modest" in that it leaves cogency to non-virtue-based considerations, but it 
also denies any special role to cogency in determining argument quality, to get a fresh look at everything else that mattersopen-mindedness, fairness, sense of proportion, contextual appropriateness, mutual respect, etc. So modest moderate VAT may not give us the whole story of argument evaluation, but it certainly provides the bulk of it, relegating cogency to little more than a footnote, albeit a necessary one.

\section{Relevance theory and VAT: Friends or foes?}

Now it is time to come back, albeit briefly, to the notion of relevance, as one of the key ingredients for cogency, at least as far as the RSA criteria are concerned (Johnson \& Blair, 1977; Johnson, 2000). As I mentioned in passing, in argumentation theory the relevance of a premise for a conclusion is typically understood in terms of the property of "having a bearing on": the notions of premissary relevance (Blair, 1992), informational relevance (Jacobs \& Jackson, 1992), premise relevance (Hitchcock, 1992), and internal relevance (Paglieri \& Castelfranchi, 2014) are all variations on this common theme. As long as relevance is understood along these lines, then the existence of bogent arguments is rather self-evident, witness the examples discussed before: the information that both Pierre and Marie Curie were physicists has an obvious bearing on the truth of the conclusion "Marie Curie was a physicist", and the same applies (jointly) to the premises "Socrates is a man" and "All men are mortals" when it comes to establish whether Socrates is mortal or not. Since the premises are also sufficient to reach the conclusion and (presumably) acceptable by the audience, then these arguments fit the bill for cogency, and yet they are intuitively very bad qua arguments - in short, they are bogent.

But if we now plug in a different, and very authoritative notion of relevance, the existence of bogent arguments become much less obvious. In the sense of relevance theory (Sperber \& Wilson, 1995), neither the Curie argument nor the Socrates syllogism would count as relevant, because now relevance is defined in cost-benefit terms, ${ }^{6}$ and in an argumentative context

${ }^{6}$ The following is a short illustration of the two-pronged nature of relevance:

(a) Everything else being equal, the greater the positive cognitive effects achieved in an individual by processing an input at a given time, the greater the relevance of the input to that individual at that time. (b) Everything else being equal, the smaller the processing effort expended by the individual to achieve those effects, the greater the

(C) Fabio Paglieri. Informal Logic, Vol. 35, No. 1 (2015), pp. 65-87. 
these contributions would have zero communicative benefits, therefore zero relevance-while of course they may still be relevant in other contexts, e.g., exemplification and philosophical analysis. Unfortunately, a comprehensive integration of relevance theory into argumentation studies is yet to come, in spite of some preliminary efforts (e.g., Iten, 2000; Oswald, 2011; Paglieri \& Woods, 2011a, 2011b; Paglieri \& Castelfranchi, 2012, 2014; Paglieri, 2013; Thierry \& Oswald, 2014 ) and a widespread awareness of the problematic nature of relevance in argumentation theory (Woods, 1992; Johnson, 2000; Botting, 2013). Nor is it this the place to tackle such a complex and delicate venture. Suffice it to say that, if the kind of relevance required for cogency was of the type described in relevance theory, then bogent arguments would become a much more elusive breed. What argument can be relevant in the sense of Sperber and Wilson, and yet also manifestly bad on intuitive grounds? Should bogency turn out to be a chimera, then we would have to conclude that cogency is, after all, a sufficient condition for argument quality. This would have profound consequences an all varieties of VAT. It would seem to be the nail in the coffin for the moderate programme, since on that view cogency would now be the whole package, both sufficient and necessary for argument quality, putting an end to any attempt to "go beyond"- at least at first sight (see below). As for the radicals, they may still insist that cogency, albeit sufficient, is not necessary for argument quality: this, however, requires providing a live specimen of goodacy, which, as discussed, is a difficult trick to pull off.

Seen in this light, relevance theory seems to spell disaster for VAT. But, on second thought, this may depend on the fact that relevance theory implicitly incorporates in its notion of relevance the very same message that VAT aims to articulate: the character of the arguers matters a lot for argument quality. After all, the target of an argument (or of any communicative act, for that matter) is explicitly mentioned by Sperber and Wilson in the very definition of relevance: it is only by considering "the positive cognitive effects achieved in an individual" and "the processing effort expended by the individual" that we can measure "the relevance of the input to that individual" (Wilson \& Sperber, 2002, p. 602, my emphasis). Here relevance is no longer a property of the argument per se, but rather a feature of the interaction between argument, context, and interpreter. While relevance theorists

relevance of the input to that individual at that time. (Sperber \& Wilson, 2002, p. 602)

(C) Fabio Paglieri. Informal Logic, Vol. 35, No. 1 (2015), pp. 65-87. 
may leave it at that, virtue theorists will want to go a step further and add that also the ability to be argumentatively relevant (that is, to produce arguments that are relevant to one's intended audience within the appropriate context) is a virtue worth having - now for the producer of the argument, rather than its interpreter.

The upshot of this analysis is the following: if relevance is understood as the property of "bearing on" (in inferential terms), then bogency is a fact of life and VAT is right in insisting that cogency is not enough to capture argument quality; if instead relevance is understood in relevance-theoretic terms (à la Sperber and Wilson, so to speak), then bogent arguments are harder to come by, and cogency is a viable candidate as a sufficient condition for argument quality. But in the latter case relevance itself now depends on features of the arguer's character-in ways yet to be specified, and not to be discussed here. So VAT comes back through the window of relevance, after being driven out through the door of sufficiency. Either way, in the end the theoretical relationship between relevance theory and VAT turns out to be amicable enough.

\section{A textbook case of conflicting argumentative virtues?}

Let us now get back to the argument by Bowell and Kingsbury (2013). If my reconstruction is correct, BK does not fare particularly well as a criticism of VAT: it is based on a definition of argument quality that virtue theorists reject, and its conclusion needs to worry only one version of VAT, i.e., ambitious moderation, out of three- too bad for Aberdein, but good for the rest of us! On the plus side, diagnosing BK helped us uncover different varieties of VAT, which hopefully may prove useful in fostering the debate.

However, I think BK and Aberdein's reaction to it (2014) epitomize a potential stand-off in the dialogue between proponents and critics of VAT, so I would like to try to intervene as an interested third party in the debate. At risk of caricaturing a serious dispute, the whole affair reminds me of the following hypothetical dialogue between Dan, a virtue theorist, and Bo, a "cogency buff", that is, a stalwart defender of cogency as the key to argument quality:

Dan: Look, there are plenty of cogent arguments that are not good in any reasonable sense. That's fascinating! It means we need more than cogency to capture argument quality.

(C) Fabio Paglieri. Informal Logic, Vol. 35, No. 1 (2015), pp. 65-87. 
Bo: Well, maybe so, but what about cogency?

Dan: Are you not listening? I have no beef with cogencykeep it, for all I care! I want to talk about everything else that matters for argument quality, and yet has nothing to do with cogency.

Bo: AHA-then you cannot account for cogency!

Dan: Jeez, some key argumentative virtue is missing here...

This is just a cartoon, of course, but it emphasizes a real problem: by insisting on cogency as key in argument evaluation, Bowell and Kingsbury (2013) focused attention on something which holds relatively little interest for the general rationale and purposes of VAT; in turn, by taking up their challenge and dealing with it, it could be said that Aberdein (2014) allowed the debate on VAT to be momentarily derailed towards matters that are, at best, tangential to it. Nor should my present efforts be regarded as being beyond reproach, since what I am doing is to argue that we should not care much whether cogency is analysable in terms of virtues, and this is tantamount to denying that we have to address the worries raised by Bowell and Kingsbury - an attitude that many argumentation theories would not find especially commendable.

It seems that what we have here is a conflict of argumentative virtues, in which nobody can honestly claim to have upheld all relevant virtues at once: no matter what the actors of this small academic drama do, they will violate at least some argumentative virtue. To put it simply, Bowell and Kingsbury, by exerting the virtue of careful critical scrutiny (focus on any unclear or defective details in a target argument), violated the virtue of relevant engagement (i.e., avoid focusing on what is manifestly of minor importance in your target argument): this, in turn, risked side-tracking the discussion on VAT. Aberdein, by closely addressing their concerns, exerted the virtue of dialectical responsiveness (address all potentially sound criticism), but failed to apply the virtue of maximal relevance in theory construction (focus primarily on what is most significant), and thus allowed the discussion to be sidetracked. Finally, my own approach tried exerting maximal relevance, but thereby failed to demonstrate dialectical responsiveness: in fact, readers will notice that whether or not VAT can account for cogency is not discussed anywhere in this paper, so Bowell and Kingsbury's arguments to that effect are simply not answered. ${ }^{7}$

\footnotetext{
${ }^{7}$ As Andrew Aberdein noted in personal communication, another way of comparing his response to $\mathrm{BK}$ and mine is in terms of Lakatos' distinction
}

(C) Fabio Paglieri. Informal Logic, Vol. 35, No. 1 (2015), pp. 65-87. 
Whether or not my reconstruction of this minor scholarly debate is correct, a general point should be apparent by now: there is no guarantee that, by exerting an argumentative virtue, the arguer will not also violate another virtue. This raises an obvious and yet crucial question for VAT: in similar conflicts of argumentative virtues, what is the virtuous option? On what grounds?

Now, that is a good challenge for VAT, not quibbling on something that VAT was never inclined to consider central, i.e., cogency. If VAT cannot deliver a solution to the frequent conflicts of argumentative virtues we encounter in everyday life, then it has a serious problem, one that applies to all varieties of VAT. Besides, the theoretical means to engage with that particular problem are within the province of VAT, and two possibilities immediately come to mind: either assuming some ordering of virtues, so that certain virtues should have precedence over others, whenever a conflict arises, or adopting some doctrine of the mean, following in Aristotle's footsteps. The former solution lends itself nicely to neat formalisms, but it raises the thorny issue of establishing criteria to generate (and possibly change over time and/or across contexts/cultures) the relevant ordering. As for the doctrine of the mean, it certainly fits nicely in any virtue-theoretical framework, but it is not easy to spell out in sufficient detail to handle real-life conflicts of argumentative virtues, which in turn may severely limit the scope of application of VAT.

Not surprisingly, Cohen listed conflicts of argumentative virtues in his to-do-list, at the end of his keynote address on VAT at OSSA 2013: "Questions such as just which virtues are needed for the different roles in arguments, how they might relate to one another, how conflicts among them might be resolved, and how they differ from skills" (p. 484, my emphasis). To explain why none of these problems were taken up in that particular paper, Cohen noted that "all of them have been addressed at length by others elsewhere" (p. 484). Unfortunately, he did not provide any exact reference for that

between positive and negative heuristics (1978): while a progressive programme can afford to ignore the negative heuristic (answering critics) in favor of the positive heuristic (exploring new applications), other programmes may be propelled forward by a lively negative heuristic (Graham Priest's dialetheism is the example Aberdein proposed, and I concur). Besides, there is no reason not to pursue both heuristics, other than time constraints. So, as I hope readers will have realized by now, my suggestion that VAT should ignore cogency as a red herring is meant in jest-although I do think that entirely forgetting the positive heuristic in favor of the negative one would do a disservice to VAT.

(C) Fabio Paglieri. Informal Logic, Vol. 35, No. 1 (2015), pp. 65-87. 
claim, and I was unable to locate a satisfactory treatment of conflicts of argumentative virtues in the relatively small literature on VAT. Thus I suspect that Cohen here was slightly exaggerating: while some of the problems he mentioned (e.g., the difference between virtues and skills) have been addressed at length by other scholars (e.g., Aberdein, 2007), some others have not, and I think conflicts of argumentative virtues belong to the latter group.

In fact, it is only in Cohen's own work that I could find a brief discussion of conflicting virtues in argument, both before (2005) and after (2009) Aberdein "invented" VAT in 2007. In a nutshell, Cohen tends to think of conflicting argumentative virtues as counterbalances: for instance, he sees an interlocutor that concedes too much and too readily to the counterpart (the "Concessionaire") as the opposite in a spectrum that starts with the "Deaf Dogmatist", that is, someone who never concedes the opponent's point, no matter what. This leads him to explicitly invoke Aristotle's doctrine of the mean, albeit only in passing: "If Aristotle is right and the golden mean is found by aiming for the opposite extreme from our natural inclinations, then we could do worse than trying to emulate the Concessionaire. The Concessionaire does, after all, listen well and has the honesty and self-confidence to acknowledge good points. If we hope for as much in our fellow interlocutors, we should cultivate it in ourselves" (2005, p. 62). In a similar vein, Cohen discusses open-mindedness and sense of proportion as two key virtues of argumentation, regulated by the same sort of balancing act; in his own words, "although it is a necessary precondition for getting the most out of our arguments, open-mindedness can also be a counterproductive trait of mind in argumentation. The problem is that arguments are open-ended in a number of different ways with the potential to be extended ad infinitum. Open-mindedness exacerbates matters. It needs the counterbalance provided by a sense of proportion" (2009, pp. 59-60).

While I do have much sympathy for this counterbalancing view of conflicting virtues in argument, Cohen's remarks are still far from providing us with a general, detailed theory of what the relevant counterbalances are, and how they are supposed to work: as far as I can see, a well-structured map of argumentative virtues is still missing. Until that map is sketched out in greater detail, the jury is still out on whether or not VAT can deliver a satisfactory understanding of conflicts of argumentative virtues. Still, the point remains: this is a worthy quest for virtue theorists, as well as a suitable target for their critics. With so many things yet to be done, not much energy

(C) Fabio Paglieri. Informal Logic, Vol. 35, No. 1 (2015), pp. 65-87. 
should be invested in less essential matters, and virtue theorists should take a lesson from Internet users: do not feed the cogency buffs!

\section{Conclusions: On what matters for VAT}

The largest portion of this paper was devoted to discussing Bowell and Kingsbury's critique of VAT, to make the point that we should stop discussing it, and more generally avoid worrying too much on whether cogency is to be understood in virtuetheoretical terms or not. This exercise may strike readers as somewhat paradoxical, and I for one would not suggest it as a good use of one's time in ordinary discussion; but it is not without precedent in philosophical debate, where establishing whether something matters for a certain issue often requires its own justification. Besides, hopefully this critical reconstruction of Bowell and Kingsbury's position offered some additional benefits to the debate on VAT: a taxonomy of different ways of being a virtue theorist on argumentation, some initial musings on the relationship between relevance theory and VAT, and an example of how argumentative virtues may conflict and thus pose a relevant challenge for VAT - not to mention elucidating the role played by bogent arguments and goodacies in the development of VAT.

Most of all, my aims were practical: I truly hope to be regarded as an impartial bystander in this particular scholarly dispute, since I do not style myself as a virtue theorist, nor do I have any strong commitment to cogency as the hallmark of argument quality. If anything, I enjoy the back and forth between proponents and critics of VAT, but only insofar as the exchange remains focused on what really matters for that particular theory - and to me, that is not cogency, for the reasons discussed above. Thus I respectfully urge both virtue theorists and their critics to skip further elaboration on virtuebased accounts of cogency, or lack thereof, and resume the really crucial work, tackling key problems such as how to account for clashes of argumentative virtues, what sort of structured set of argumentative virtues we should consider relevant, and why (for more comprehensive lists of key open problems, see Aberdein, 2007; Cohen, 2013). And to newcomers to this fascinating area of argumentation theory, I would like to offer two pieces of advice:

1. If you are interested in VAT, do not approach from the cogency angle.

(C) Fabio Paglieri. Informal Logic, Vol. 35, No. 1 (2015), pp. 65-87. 
2. If you are a cogency buff, probably you will not find much satisfaction in VAT-live with it!

Acknowledgements: I am grateful to Andrew Aberdein, Daniel Cohen, David Godden, Frank Zenker, and two anonymous reviewers for providing helpful suggestions and cogent criticism on a previous version of this paper. I also had the good fortune of presenting it at the ISSA 2014 conference in Amsterdam, thanks to the financial support provided by the research project PRISMA: Interoperable Cloud Platforms for Smart Government, funded by the Italian Ministry of Education, University and Research (MIUR). As Daniel Cohen noted in personal communication (admittedly, over drinks...), that conference presentation was graced by a truly virtuous audience, whose critical suggestions greatly improved my ideas on the subject. Any residual shortcoming, unsurprisingly, is to be blamed on my argumentative vices, of which I have no shortage.

\section{References}

Aberdein, A. (2007). Virtue argumentation. In F.H. van Eemeren, J.A. Blair, C.A. Willard \& B. Garssen (Eds.), Proceedings of the Sixth Conference of the International Society for the Study of Argumentation (pp. 15-19). Amsterdam: Sic Sat.

Aberdein, A. (2010a). Virtue in argument. Argumentation, 24(2), 165-179.

Aberdein, A. (2010b). Observations on sick mathematics. In B. Van Kerkhove, J. De Vuyst \& J.P. Van Bendegem (Eds.), Ph ilosophical perspectives on mathematical practice (pp. 269300). London: College Publications.

Aberdein, A. (2014). In defence of virtue: The legitimacy of agent-based argument appraisal. Informal Logic, 34(1), 7793.

Allen, D. (1998). Should we assess the basic premises of an argument for truth or acceptability? In H.V. Hansen, C.W. Tindale, \& A. Colman (Eds.), Argumentation \& Rhetoric (CD-Rom). St. Catharines, ON: OSSA.

Battaly, H. (2010). Attacking character: Ad hominem argument and virtue epistemology. Informal Logic, 30(4), 361-390.

Blair, J.A. (1992). Premissary relevance. Argumentation, 6, 203217.

Botting, D. (2013). The irrelevance of relevance. Informal Logic, 33(1), 1-21.

(C) Fabio Paglieri. Informal Logic, Vol. 35, No. 1 (2015), pp. 65-87. 
Bowell, T., \& Kingsbury, J. (2013). Virtue and argument: Taking character into account. Informal Logic, 33(1), 22-32.

Cohen, D. (1995). Argument is war... and war is hell: Philosophy, education, and metaphors for argumentation. Informal Logic, 17(2), 177-188.

Cohen, D. (2004). Arguments and metaphors in philosophy. Lanham, MD: University Press of America.

Cohen, D. (2005). Arguments that backfire. In D. Hitchcock, \& D. Farr (Eds.), The uses of argument (pp. 58-65). Hamilton, ON: OSSA.

Cohen, D. (2009). Keeping an open mind and having a sense of proportion as virtues in argumentation. Cogency, 1, 49-64.

Cohen, D. (2013). Virtue, in context. Informal Logic, 33(4), 471-485.

Finocchiaro, M.A. (2013). Meta-argumentation: An approach to logic and argumentation theory. London: College Publications.

Foot, P. (1978). Virtues and vices. Oxford: Blackwell.

Govier, T. (1985). A practical study of argument. Belmont: Wadsworth.

Hitchcock, D. (1992). Relevance. Argumentation, 6, 251-270.

Hursthouse, R. (1999). On virtue ethics. Oxford: Oxford University Press.

Iten, C. (2000). The relevance of Argumentation Theory. Lingua, 110(9), 665-699.

Jacobs, S., \& Jackson, S. (1992). Relevance and digressions in argumentative discussion: A pragmatic approach. Argumentation, 6, 161-176.

Johnson, R.H. (1990). Hamblin on the standard treatment. Philosophy \& Rhetoric, 23, 153-167.

Johnson, R.H. (2000). Manifest rationality: A pragmatic theory of argument. Mahwah: LEA.

Johnson, R.H., \& Blair, J.A. (1977). Logical self-defense. Toronto: McGraw-Hill Ryerson.

Lakatos, I. (1978). The methodology of scientific research programmes. Cambridge: Cambridge University Press

MacIntyre, A. (1981). After virtue. Notre Dame: University of Notre Dame Press.

Oswald, S. (2011). From interpretation to consent: Arguments, beliefs and meaning. Discourse Studies, 13(6), 806-814.

Paglieri, F. (2013). Choosing to argue: Towards a theory of argumentative decisions. Journal of Pragmatics, 59(B), 153163.

Paglieri, F., \& Castelfranchi, C. (2012). Trust in relevance. In S. Ossowski, G. Vouros, F. Toni, (Eds.), Proceedings of 
Agreement Technologies 2012 (pp. 332-346). Tilburg: CEUR-WS.org.

Paglieri, F., \& Castelfranchi, C. (2014). Trust, relevance, and arguments. Argument \& Computation, 5(2-3), 216-236.

Paglieri, F., \& Woods, J. (2011a). Enthymematic parsimony. Synthese, 178, 461-501.

Paglieri, F., \& Woods, J. (2011b). Enthymemes: From reconstruction to understanding. Argumentation, 25(2), 127139.

Pritchard, D.H. (2003). Virtue epistemology and epistemic luck. Metaphilosophy, 34(1-2), 106-130.

Pritchard, D.H. (2008). Virtue epistemology and epistemic luck, revisited. Metaphilosophy, 39(1), 66-88.

Pritchard, D.H. (2012). Anti-luck virtue epistemology. Journal of Philosophy, 109(3), 247-279.

Seligman, M.E.P., \& Csikszentmihalyi, M. (2000). Positive psychology: An introduction. American Psychologist, 55(1), 5-14.

Sosa, E. (2007). A virtue epistemology: Apt belief and reflective knowledge, Vol. I. Oxford: Oxford University Press.

Sperber, D., Wilson, D. (1995). Relevance: Communication and cognition. 2nd ed., Malden: Basil Blackwell.

Thierry, H., \& Oswald, S. (Eds.) (2014). Rhétorique et cognition: Perspectives théoriques et stratégies persuasives / Rhetoric and cognition: Theoretical strategies and persuasive strategies (bilingual volume). Bern: Peter Lang.

Tindale, C.W. (2007). Fallacies and argument appraisal. Cambridge: Cambridge University Press.

Vorobej, M. (2006). A theory of argument. Cambridge: Cambridge University Press.

Walton, D. (1998). Ad hominem arguments. Tuscaloosa, AL: The University of Alabama Press.

Wilson, D., \& Sperber, D. (2002). Truthfulness and relevance. Mind, 111, 583-632.

Woods, J. (1992). Apocalyptic relevance. Argumentation, 6, 189-202.

Woods, J. (2007). Lightening up on the ad hominem. Informal Logic, 27(1), 109-134.

Zagzebski, L. (1996). Virtues of the mind. Cambridge: Cambridge University Press. 